\title{
Agronomical evaluation of local Tunisian almond cultivars and their breeding prospects
}

\author{
H. Gouta ${ }^{1}$, E. Ksia ${ }^{2}$, M.M. Ayachi ${ }^{1}$ and P. Martínez-Gómez ${ }^{3}$ \\ ${ }^{1}$ Olive Tree Institute, Sfax, Tunisia \\ ${ }^{2}$ Laboratoire de Biologie des Plantes et Biotechnologies, Faculté des Sciences, Campus Universitaire, El Manar, Tunis, Tunisia \\ ${ }^{3}$ Department of Plant Breeding, CEBAS-CSIC, Espinardo, Murcia, Spain
}

\section{Summary}

Almonds have been cultivated in Tunisia since ancient times. Due to increasingly severe dry conditions, the local almond gene pool has significantly decreased since the 1980's. In order to rescue the remaining almond germplasm and to investigate the existing agronomical variation in Tunisia, a survey was undertaken several years ago to identify and preserve the traditional almond cultivars. In this study, 52 local almond cultivars and ecotypes were evaluated for three consecutive years, and 18 different tree, kernel and nut traits were observed. Results show a great diversity of almond ecotypes and cultivars in Tunisia. Kernel weight and size and adaptation to dry conditions are the most interesting qualities of this local germplasm. However, self-incompatibility, early flowering and the presence of double kernels are the most common obstacles for using this germplasm in breeding. Furthermore, principal component analysis was used to identify morphological variation patterns and to classify the genotypes. In this analysis, the first three retained principal components were found to explain more than $56 \%$ of the total variance. The main nut traits, such as length, thickness and size, were strongly associated with the first principal component. However, shell retention, shelling percentage and kernel weight had the highest loadings for the second principal component. Finally, cluster analysis revealed four groups for the almond cultivars studied, but no discrimination among genotypes according to their origin was observed. Results show the great pomological variation of local Tunisian almond cultivars and their breeding value for increasing Tunisian almond production and as source of drought resistance.

Keywords

Prunus, almond local ecotypes, breeding, germplasm, drought resistance, agronomical diversity

\section{Introduction}

Almond [Prunus dulcis (Mill.) D.A. Webb, syn. P. amygdalus (L.) Batsch] is an ancient domesticated tree species that has co-evolved with human civilization. This fruit tree species is used for its edible seeds (Gradziel and Martínez-Gómez, 2013). Today almonds are cultivated in 50 countries (http:// faostat.fao.org), not only for the fresh and processed food industry but also as a functional food with both nutritional

\section{Significance of this study}

What is already known on this subject?

- The rich Tunisian almond germplasm evaluated through molecular markers.

What are the new findings?

- The agronomical evaluation of the rich Tunisian almond germplasm under local drought conditions.

What is the expected impact on horticulture?

- The breeding possibilities of this rich Tunisian almond germplasm and the prospects for new productive with higher quality almond releases adapted to drought conditions.

and medical properties, including healthy blood lipids levels, anti-inflammatory and hypocholesterolemic properties (Poonam et al., 2011; García et al., 2016; Musa-Velasco et al., 2016).

Almond production in Tunisia is based on the use of locally adapted clones and traditional management practices with minimal to no inputs. These local cultivars are commonly grown in areas between $33^{\circ}$ and $36^{\circ} \mathrm{N}$ and $8^{\circ}$ and $10^{\circ} \mathrm{E}$, and at altitudes between 13 and $400 \mathrm{~m}$. These almond production areas include a humid climate zone in the north of Tunisia, with an average annual rainfall of more than $700 \mathrm{~mm}$, and a semi-arid climate zone in the centre that receives around $200 \mathrm{~mm}$ of rain per year (Figure 1).

The cultivation of this species was introduced in Tunisia by the Phoenicians in the $12^{\text {th }}$ century B.C. Starting in the early $20^{\text {th }}$ century, many pomologists identified genotypes that were later propagated and considered as cultivars. This was the case in Sfax (southeast Tunisia) for the main cultivars, which are called 'Sfaxien' cultivars: 'Abiodh', 'Ksantini', 'Grosse Tendre', 'Guernghzel' and 'Achaak' (Grasselly and Crossa-Raynaud, 1980). Currently, we have about 20 million almond trees in Tunisia occupying more than 250,000 ha. Almond cultivation is mostly non-irrigated with kernel yields of around $350 \mathrm{~kg} \mathrm{ha}^{-1}$, which is much lower than the 2,300 $\mathrm{kg} \mathrm{ha}^{-1}$ in the US, where the production (limited to California) is much more intensive and exclusively irrigated (http:// faostat.fao.org).

Grasselly and Crossa-Raynaud (1980) were the first to briefly describe the Tunisian germplasm diversity and to give an overview of the morphological characteristics (shell hardness, fruit shape, kernel percentage and blooming time) of several local almond cultivars. Since then, the need to characterise and preserve the local germplasm 
has increased, and a survey was therefore launched in the main almond producing regions. Results not only prove the existence of significant diversity, but also describe new, previously unknown landraces (Gouta et al., 2010, 2011). In addition, recent data using molecular markers (Gouta et al., 2008, 2012) have confirmed this large genetic diversity and underscored the importance of characterising the local germplasm. Furthermore, the adaptation of the local Tunisian almond cultivars to very dry environments indicates their potential as a resistance source for drought conditions.

The objective of this work was to perform a more indepth assessment of the agronomical diversity of local almond germplasm from different regions in Tunisia than has been done before and to evaluate the breeding prospects of these local cultivars.

\section{Materials and methods}

\section{Local almond cultivars evaluated}

A total of 52 Tunisian almond cultivars and ecotypes representing the variability of this species in the country were included in this study (Table 1). These ecotypes came from four different sites in Sidi Bouzid in the Centre-west of Tunisia (Ben Aoun, Ouled Haffouz, Regueb and Sidi Bousid East); seven came from Bizerte in the Northeast; and the rest were either collected from the South (Sfax, Nefta and Tozeur) or were of unknown origin (Table 2; Figure 1). The Italian cultivar 'Tuono' was included in this study as reference cultivar.

\section{Agronomical evaluation}

Twenty different tree and kernel traits were included in this study. To evaluate these traits, we randomly selected three trees and 50 kernels from each cultivar and ecotype over a 3-year period. The five tree traits of agronomical interest we observed include self-compatibility, evaluated by bagging (self-compatible or self-incompatible); flowering date [very early (last week of January), early (first week of February), intermediate (second and third week of February) and late (last week of February)]; flowering duration (days); tree vigour (weak growth, intermediate, significant); and growth habit (very upright, upright, spreading, dropping, weeping). The four qualitative kernel traits of agronomical interest we observed include double kernels (low, medium, high and very high percentage); shell hardness (very hard, hard, semi-hard, soft); shell shape (round, oval, oblong, cordate, extremely narrow); and kernel bitterness (sweet, slightly bitter and bitter). Finally, other eleven quantitative kernel traits observed include nut length ( $\mathrm{mm}$ ); nut thickness $(\mathrm{mm})$; shell retention [raw whole unpeeled almond kernels retained in a scale from 1 (none retained) to 10 (maximum retained)]; shell softness (between 0 and 10); nut size [in a scale from 1 (small) to 10]; kernel length (mm); kernel thickness (mm); kernel weight $(\mathrm{g})$; shelling percentage (relation between shell and kernel in \%); double kernels (\%) and aborted kernels ( $\%$ of shell without a kernel).

\section{Statistical analyses}

Descriptive statistical analyses were carried out using SPSS 16.0 software (IBM-SPSS 2007). Principal component analysis (PCA) was performed using Microsoft ${ }^{\circledR}$ Excel 2000/ XLSTAT-Pro (Version 2010, Addinsoft, Inc., Brooklyn, NY, USA). In addition, hierarchic classification was performed using NTSYS 2.1 (Rohlf, 2004). Both analyses made it possible to compare and perform cluster analyses of the evaluated traits. In addition, the relation between variables (associations or oppositions between them) and the individual repartition (cultivars and ecotypes) was calculated using the Pearson correlation coefficient.

\section{Results and discussion}

\section{Variability of almond cultivars and ecotypes}

All the local genotypes were found to be selfincompatible, and flowering dates ranged from very early to intermediate (Table 1). The trees observed in this study showed different habits, varying from extremely upright to weeping. The majority of the described trees (85\%) had an upright, spreading or dropping form, while a minority (15\%) had an extremely upright or weeping habit. Concerning vigour, the majority of the trees $(70 \%)$ showed intermediate performance. Tree vigour ranged from weak to strong.

Double kernels were observed in some cultivars when the two ovules were fertilised and both continued to develop. This is considered to be a negative trait because it results in two deformed kernels of low commercial value (Table 3). On the other hand, average kernel weight varied between 0.8 and $1.7 \mathrm{~g}$, with an overall average weight of approximately $1 \mathrm{~g}$. Such medium high-kernel weights (around $1.5 \mathrm{~g}$ ) are a trait of great interest considering the severity of the climate in this country.

Concerning other nut characteristics, the distribution of nut length was symmetric averaging around $34 \mathrm{~mm}$. This average ranged between 26 and $36 \mathrm{~mm}$ for 41 of the 53 genotypes studied (83\%). In contrast, the distribution for nut thickness was asymmetric, and $75 \%$ of the genotypes studied had thickness values between 14 and $18 \mathrm{~mm}$. In terms of nut size, most of the fruits had a medium to large size $(83 \%)$. However, shell softness was intermediate for more than half of the genotypes (27) (Figures 2 and 3).

TABLE 2. Climatic characteristics of the locations where almond cultivars and ecotypes have been collected.

\begin{tabular}{llcccc}
\hline Location & Bioclimatic stage & $\begin{array}{c}\text { Average } \\
\text { temperature }\end{array}$ & $\begin{array}{c}\text { Minimum/maximum } \\
\text { temperature }\end{array}$ & $\begin{array}{c}\text { Average } \\
\text { precipitation }\end{array}$ & $\begin{array}{c}\text { Number of rain } \\
\text { days year }\end{array}$ \\
\hline Ben Aoun & Arid with cold winter & $17.6^{\circ} \mathrm{C}$ & $6^{\circ} \mathrm{C} / 36^{\circ} \mathrm{C}$ & $234 \mathrm{~mm}$ & 34 \\
Bizerte & Subhumid & $16.2^{\circ} \mathrm{C}$ & $6.9^{\circ} \mathrm{C} / 31.6^{\circ} \mathrm{C}$ & $656 \mathrm{~mm}$ & 111 \\
Nefta & Saharian & $20.9^{\circ} \mathrm{C}$ & $4.8^{\circ} \mathrm{C} / 39.5^{\circ} \mathrm{C}$ & $94 \mathrm{~mm}$ & 21 \\
Ouled Haffouz & Arid with cold winter & $17.8^{\circ} \mathrm{C}$ & $8.9^{\circ} \mathrm{C} / 27.4^{\circ} \mathrm{C}$ & $230 \mathrm{~mm}$ & 57 \\
Regueb & Arid with warm winter & $18.2^{\circ} \mathrm{C}$ & $9.7^{\circ} \mathrm{C} / 27.2^{\circ} \mathrm{C}$ & $197 \mathrm{~mm}$ & 64 \\
Sfax & Arid with warm winter & $18.6^{\circ} \mathrm{C}$ & $5.8^{\circ} \mathrm{C} / 32.2^{\circ} \mathrm{C}$ & $134 \mathrm{~mm}$ & 50 \\
Sidi Bouzid Est & Arid with cold winter & $17.9^{\circ} \mathrm{C}$ & $8.8^{\circ} \mathrm{C} / 27.6^{\circ} \mathrm{C}$ & $241 \mathrm{~mm}$ & 58 \\
Tozeur & Saharian & $21.2^{\circ} \mathrm{C}$ & $5.4^{\circ} \mathrm{C} / 39.4^{\circ} \mathrm{C}$ & $93 \mathrm{~mm}$ & 20 \\
\hline
\end{tabular}


TABLE 1. List and origin of almond cultivars and ecotypes characterised in this study and the main tree traits evaluated.

\begin{tabular}{|c|c|c|c|c|c|c|}
\hline Cultivar & Location & $\begin{array}{c}\text { Self- } \\
\text { compatibility* }\end{array}$ & $\begin{array}{c}\text { Flowering } \\
\text { date }\end{array}$ & $\begin{array}{l}\text { Flowering } \\
\text { duration }\end{array}$ & $\begin{array}{c}\text { Tree } \\
\text { vigor }\end{array}$ & $\begin{array}{c}\text { Growth } \\
\text { habit }\end{array}$ \\
\hline Abiodh de Sfax & Sfax & $\mathrm{SI}$ & Very early & 11 & Intermediate & Spreading \\
\hline Abiodh Ras Djebel & Bizerte & SI & Early & 11 & Intermediate & Spreading \\
\hline Achaak Abiodh & Sfax & SI & Very early & 13 & Important & Upright \\
\hline Achaak M. & Sfax & SI & Very early & 9 & Intermediate & Dropping \\
\hline Amara 1 & Ben Aoun & SI & Early & 9 & Important & Weeping \\
\hline Amara 5 & Ben Aoun & SI & Early & 11 & Intermediate & Upright \\
\hline B.F.1 & Ouled Haffouz & SI & Early & 12 & Intermediate & Dropping \\
\hline B200 & Unknown & SI & Intermediate & 9 & Weak & Very upright \\
\hline B202 & Unknown & SI & Intermediate & 9 & Weak & Upright \\
\hline B203 & Unknown & SI & Early & 9 & Weak & Upright \\
\hline B204 & Unknown & SI & Early & 9 & Important & Upright \\
\hline Belgacem N.1 & Sidi Bouzid & SI & Early & 10 & Intermediate & Spreading \\
\hline Belgacem N.2 & Sidi Bouzid & SI & Early & 10 & Intermediate & Spreading \\
\hline Ben Cherifa 2 & Regueb & SI & Early & 8 & Intermediate & Upright \\
\hline Ben Cherifa 3 & Regueb & SI & Early & 12 & Important & Dropping \\
\hline Ben Salah 1 & Ouled Haffouz & SI & Very early & 4 & Intermediate & Dropping \\
\hline Ben Thabet Ch. 1 & Ouled Haffouz & SI & Early & 8 & Intermediate & Spreading \\
\hline Ben Thabet Ch. 2 & Ouled Haffouz & SI & Early & 9 & Intermediate & Upright \\
\hline Ben Thabet Ch. 3 & Ouled Haffouz & SI & Early & 12 & Intermediate & Dropping \\
\hline Blanco & Bizerte & SI & Very early & 14 & Intermediate & Upright \\
\hline Bouchouka K.F. & Ouled Haffouz & $\mathrm{SI}$ & Early & 14 & Intermediate & Dropping \\
\hline Cheikh Sadok 1 & Regueb & SI & Very early & 11 & Important & Weeping \\
\hline Cheikh Sadok 3 & Regueb & SI & Very early & 11 & Intermediate & Spreading \\
\hline Chtioui 1 & Ouled Haffouz & $\mathrm{SI}$ & Early & 10 & Intermediate & Dropping \\
\hline Chtioui 4 & Ouled Haffouz & SI & Very early & 8 & Intermediate & Weeping \\
\hline Dillou & Bizerte & SI & Very early & 14 & Intermediate & Weeping \\
\hline Elloumi & Sfax & SI & Very early & 11 & Weak & Spreading \\
\hline Faggoussi & Bizerte & SI & Early & 9 & Intermediate & Spreading \\
\hline Fekhfekh & Sfax & SI & Very early & 11 & Intermediate & Upright \\
\hline Grosse Tendre Sfax & Sfax & SI & Very early & 16 & Intermediate & Spreading \\
\hline Guerneghzel C.H. & Sfax & SI & Early & 11 & Intermediate & Dropping \\
\hline Guernghzel B.N. & Sidi Bouzid & SI & Early & 12 & Intermediate & Spreading \\
\hline Harth Nefta & Nefta & SI & Very early & 15 & Weak & Spreading \\
\hline Houcine B.N. 2 & Ben Aoun & SI & Very early & 7 & Intermediate & Spreading \\
\hline Khoukhi Bizerte & Bizerte & SI & Very early & 15 & Intermediate & Spreading \\
\hline Khoukhi INRAT & Bizerte & SI & Early & 10 & Intermediate & Dropping \\
\hline Ksontini & Sfax & SI & Very early & 11 & Intermediate & Dropping \\
\hline Lakhdhar & Ben Aoun & SI & Very early & 10 & Important & Weeping \\
\hline Lessen Asfour & Bizerte & SI & Early & 10 & Intermediate & Upright \\
\hline Mahsouna & Sfax & SI & Very early & 11 & Intermediate & Upright \\
\hline Porto Farina* & Ouled Haffouz & SI & Very early & 10 & Intermediate & Upright \\
\hline Ras Bouma F. & Ouled Haffouz & SI & Very early & 10 & Intermediate & Dropping \\
\hline Sahnoun $\mathrm{CH}$. & Sfax & SI & Very early & 12 & Intermediate & Very upright \\
\hline Tlili 5 & Ben Aoun & SI & Early & 9 & Important & Weeping \\
\hline Tlili 6 & Ben Aoun & $\mathrm{SI}$ & Early & 8 & Intermediate & Spreading \\
\hline Tlili 8 & Ben Aoun & SI & Early & 14 & Intermediate & Spreading \\
\hline Tlili 9 & Ben Aoun & SI & Very early & 11 & Intermediate & Dropping \\
\hline Tozeur 1 & Tozeur & SI & Very early & 16 & Important & Upright \\
\hline Tozeur 2 & Tozeur & SI & Very early & 14 & Intermediate & Upright \\
\hline Tozeur 4 & Tozeur & SI & Very early & 12 & Important & Upright \\
\hline Triki & Sfax & $\mathrm{SI}$ & Very early & 11 & Weak & Spreading \\
\hline Tuono & Italy & SC & Late & 11 & Important & Spreading \\
\hline Zahaaf & Sfax & $\mathrm{SI}$ & Very early & 14 & Intermediate & Spreading \\
\hline
\end{tabular}

* SI Self-incompatible, SC Self-compatible. 


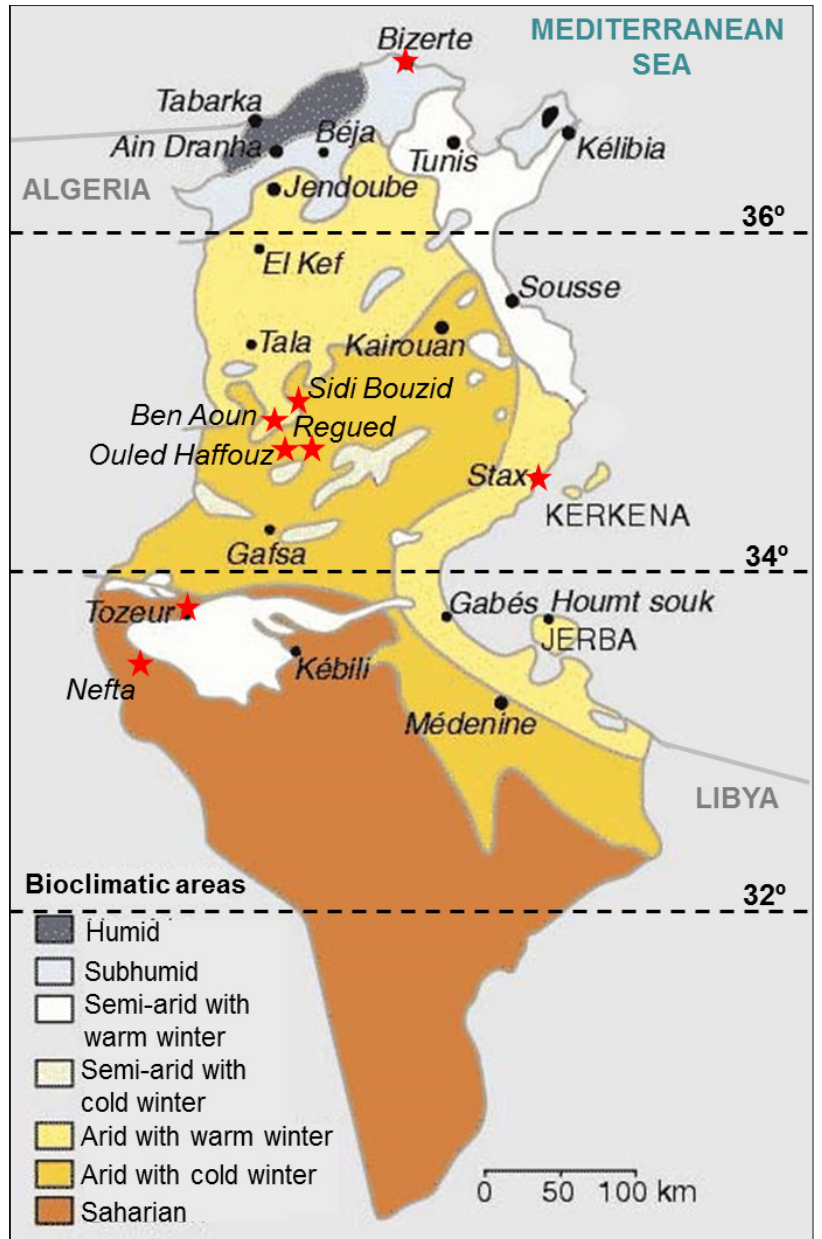

FIGURE 1. Map of bioclimatic areas in Tunisia (from the Information system on desertification in Tunisia, http:// www.environnement.nat.tn) and geographical locations (indicated with a red star) of the local almond cultivars collected and assayed.

Regarding the kernel, length and thickness, distributions were symmetric, with $75 \%$ of the genotypes showing a length of between 22 and $28 \mathrm{~mm}$ and a thickness of between 6.5 and $8.5 \mathrm{~mm}$. Shelling percentage also showed symmetric distribution, with an average value of around $40 \%$. In fact, 43 genotypes (81\%) showed a shelling percentage of between 30 and $50 \%$ (Figure 3 ).

For nut size and shell retention, most of the fruits were medium to large in size (83\%) and did not retain their shells (89\%). Most of the genotypes had a kernel weight average of less than $1.4 \mathrm{~g}$ (Figure 3; Table 3). Figure 3 shows that the majority of the trees (85\%) had an upright (15 genotypes), spreading (17) or dropping form (13), while a minority (15\%) had an extremely upright (2) or weeping habit (6) (Figure 3).

Finally, the parameters directly related to commercial value (double kernel, aborted kernel, and one aborted kernel) presented left-skewed (asymmetric) distribution (Figure 3). Indeed, out of the 53 genotypes studied, 37 had a double kernel rate of less than $20 \%$. A high rate for this parameter affected the homogeneity of the kernel and consequently decreased the kernel quality. Our results show that $70 \%$ of the population studied has kernels of high commercial value.

Furthermore, 45 genotypes ( $84 \%$ of the population) had an aborted kernel percentage of between 0 and $3 \%$. The aborted kernel percentage ranged between 0 and $5 \%$ for 39 genotypes (73\%) (Figure 3). Sorkheh et al. (2010) associated these traits with the fertility degree. Consequently, it seems that a majority of the genotypes studied are highly fertile. Finally, shelling percentage showed symmetric distribution with an average value of around $40 \%$. In fact, 43 genotypes (81\%) showed a shelling percentage ranging from 30 to $50 \%$.

This large phenotypic diversity was already expected, sincealmond is self-incompatible and traditional farmerstend to propagate almond by seed. Similarly, large distributions have been observed in native germplasm characterised using morphological traits in Morocco (Lansari et al., 1994), Lebanon (Talhou et al., 2000; Chalak et al., 2007), Italy (De Giorgio et al., 2007), Turkey (Ak et al., 2005), Iran (Fathi et al., 2008; Sorkheh et al., 2010) and Serbia (Čolić et al., 2012).

\section{Correlation among morphological traits}

Relationships between 11 quantitative kernel parameters were studied and Pearson correlations were calculated (Table 4). Significant correlations $(P=0.01)$ were found among most of the studied traits, but high values were only noted in some cases. Indeed, positive correlations were recorded for most variables related to nut and kernel size, which is in accordance with the findings in other studies (Čolić et al., 2012). These data can be exploited either by breeding programmes or for facilitating the identification of almond ecotypes during field surveys. Furthermore, the kernel weight was found to be highly correlated with the nut thickness (0.659). Other correlations were recorded for double kernel percentage with kernel thickness $(0.411)$ and with aborted kernel $(0.410)$.

Some negative correlation coefficient values were obtained for shelling percentage and nut thickness (-0.513). No correlation was observed between kernel weight and shell softness, so these traits were considered to be independent. These results are in accordance with those reported by Sorkheh et al. (2010) and Sanchez-Pérez et al. (2007), who noted that shell softness does not affect the weight of the kernel.

Correlation results show that nut thickness could be a powerful indicator for selecting high-performing almond genotypes in the field (Sorkheh et al., 2009). High absolute correlation values between morphological and pomological traits related to fruit, nut, leaf size and phenology have also been established for other species of the genus Prunus, such as apricot (Badenes et al., 1998), peach (Nikolić et al., 2010), sour cherry (Krahl et al., 1991) and sweet cherry (Hjalmarsson et al., 2000).

\section{Principal component and cluster analysis}

In general, principal component analysis (PCA) is performed to reduce the number of effective traits and for group identification. In this study, when using the 11 analysed parameters, the first three principal components accounted for $41 \%$ of the total variance, and selecting according to the highest eigenvectors increased the rate to $56 \%$. The first PC explained $25 \%$ of the morphological variation, while the second explained $17 \%$ and the third $14 \%$ (Table 5).

According to correspondence between the principal components (PCs) and the original characteristics and eigenvectors, nut length, nut thickness and nut size make the biggest contribution to the positive PC1. As a consequence, all of the genotypes 'Zahaaf', 'Elloumi', 'Ras Bouma', 'Fekhfekh', 'Ghernghzel CH.,' 'Tozeur1', 'Tlili 8', 'Tlili 9' and 'Chtioui 4' had a big nut size but a relatively high level of aborted kernels. Conversely, 'Abioth Ras Djebel', 'Belgacem N.1', 'Tozeur 2', 
TABLE 3. Evaluation of qualitative kernel traits in the Tunisian almond cultivars and ecotypes evaluated.

\begin{tabular}{|c|c|c|c|c|}
\hline Cultivar & Double kernel & Shell hardness & Shell shape & Kernel bitterness \\
\hline Abiodh de Sfax & Medium & Semi hard & Oblong & Sweet \\
\hline Abiodh Ras Djebel & Low & Soft & Oblong & Sweet \\
\hline Achaak Abiodh & Low & Semi hard & Oblong & Sweet \\
\hline Achaak M. & High & Semi hard & Oblong & Slightly bitter \\
\hline Amara 1 & Medium & Soft & Cordate & Sweet \\
\hline Amara 5 & High & Hard & Cordate & Sweet \\
\hline B.F.1 & Medium & Semi hard & Oblong & Sweet \\
\hline B200 & Medium & Semi hard & Cordate & Sweet \\
\hline B202 & Low & Semi hard & Oblong & Sweet \\
\hline B203 & Low & Semi hard & Oblong & Sweet \\
\hline B204 & High & Semi soft & Oblong & Sweet \\
\hline Belgacem N.1 & Low & Semi hard & Cordate & Sweet \\
\hline Belgacem N.2 & Very high & Hard & Cordate & Sweet \\
\hline Ben Cherifa 2 & Medium & Soft & Cordate & Sweet \\
\hline Ben Cherifa 3 & High & Semi hard & Oval & Sweet \\
\hline Ben Salah 1 & Medium & Semi hard & Oval & Sweet \\
\hline Ben Thabet Ch. 1 & Null & Semi hard & Oblong & Sweet \\
\hline Ben Thabet Ch. 2 & Low & Very hard & Oblong & Sweet \\
\hline Ben Thabet Ch. 3 & Low & Semi hard & Oblong & Sweet \\
\hline Blanco & Medium & Semi hard & Oblong & Sweet \\
\hline Bouchouka K.F. & Very high & Soft & Cordate & Sweet \\
\hline Cheikh Sadok 1 & Medium & Semi soft & Oval & Sweet \\
\hline Cheikh Sadok 3 & Low & Hard & Oblong & Sweet \\
\hline Chtioui 1 & Medium & Semi hard & Oval & Sweet \\
\hline Chtioui 4 & Medium & Soft & Cordate & Sweet \\
\hline Dillou & Medium & Soft & Oval & Sweet \\
\hline Elloumi & Medium & Semi hard & Cordate & Sweet \\
\hline Faggoussi & Null & Semi soft & Cordate & Sweet \\
\hline Fekhfekh & High & Hard & Oblong & Sweet \\
\hline Grosse Tendre Sfax & Low & Hard & Cordate & Sweet \\
\hline Guerneghzel C.H. & Medium & Hard & Extremely narrow & Sweet \\
\hline Guernghzel B.N. & Medium & Hard & Extremely narrow & Sweet \\
\hline Harth Nefta & Medium & Semi hard & Cordate & Sweet \\
\hline Houcine B.N. 2 & Very high & Semi soft & Oblong & Sweet \\
\hline Khoukhi Bizerte & High & Semi soft & Oblong & Slightly bitter \\
\hline Khoukhi INRAT & Null & Semi hard & Oblong & Sweet \\
\hline Ksontini & Low & Semi hard & Oblong & Slightly bitter \\
\hline Lakhdhar & Very high & Semi hard & Cordate & Sweet \\
\hline Lessen Asfour & Null & Semi soft & Cordate & Sweet \\
\hline Mahsouna & High & Semi hard & Oblong & Sweet \\
\hline Porto Farina* & Null & Soft & Oval & Sweet \\
\hline Ras Bouma F. & Very high & Semi hard & Oval & Sweet \\
\hline Sahnoun $\mathrm{CH}$. & Low & Semi hard & Cordate & Sweet \\
\hline Tlili 5 & Medium & Semi hard & Oblong & Sweet \\
\hline Tlili 6 & Medium & Hard & Oval & Sweet \\
\hline Tlili 8 & High & Hard & Cordate & Sweet \\
\hline Tlili 9 & High & Hard & Round & Sweet \\
\hline Tozeur 1 & Null & Hard & Oblong & Sweet \\
\hline Tozeur 2 & High & Soft & Round & Sweet \\
\hline Tozeur 4 & Low & Hard & Oblong & Sweet \\
\hline Triki & High & Hard & Cordate & Sweet \\
\hline Tuono & Medium & Hard & Oval & Slightly bitter \\
\hline Zahaaf & Medium & Hard & Oval & Sweet \\
\hline
\end{tabular}


'Dillou', 'Khoukhi INRAT', Cheikh Sadok 1', 'BF. 1', 'Tlili 5', and 'Houcine B.N.2' had relatively smaller nuts and low aborted kernel rates (Figure 4).

The second PC showed that the percentages of shelling percentage, kernel length and average kernel weight had the highest correlation. Indeed, the genotypes represented in the positive part (upper part of the axis), such as 'Dillou', 'Fagoussi', 'Lesen Asfour', 'Porto Farina' and 'Khoukhi Bizerte', were classified as soft shelled with significant commercial appeal (high shelling percentage and high kernel weight), while 'Tozeur 2', 'Houcine B.N.2', 'Ben Thabet Ch.2', 'Tlili 8' and 'Tlili 9' were hard shelled.

The percentage of double kernels together with one aborted kernel were the major variables composing PC3 and therefore contributed to the variability (14\%). Concerning the contribution of ecotypes to the total variance, it seems that 'Khoukhi Bizerte', 'Tozeur 2', 'Tlili 9', and 'B200' have the highest contribution to axis 3 with a relatively high double kernel rate. The ecotypes 'Abiodh Sfax', 'Achaak', 'Dillou', 'Elloumi', 'Faggoussi', 'Guernghzel CH', 'Lesen Asfour', 'Ras Bouma', 'Tozeur 1', 'Tozeur 4', 'Tlili 5' and 'Ben Thabet Ch. 2' have a very low level of contribution and are close to 'Tuono' (Figure 4).

PCA analysis results agree with those of Talhouk et al. (2000) and Sorkheh et al. (2009), who showed that nut traits were consistent in their contribution to the first component and could be used as a tool for almond germplasm characterisation. In addition, cultivar grouping was independent of the area of prospection. Our results indicate a high level of almond diversity in Tunisia that is widely spread around the country.

A cluster analysis based on Euclidian distances was also carried out to obtain the association between the genotypes. After standardising the data, the similarity trend observed made it possible to identify four main groups: A, B, C, and $D$ (Figure 5). Results showed a wide distribution of all the genotypes assayed in the four clusters.

The local ecotypes used in our study were present in the four clusters in association with the traditional local cultivars and the Italian cultivar 'Tuono' (cluster D). In cluster D, 34 Tunisian genotypes (64\%) were grouped with cultivars and ecotypes from Northern Tunisia ('Dillou', 'Blanco', 'Faggoussi', 'Lesen Asfour'); Central Tunisia ('Ben Thabet 1', 'Ben Thabet 2', 'Ben Thabet 3', 'Ben Cherifa 2', 'Guerghzel BN.,' 'Tlili 4' and 'Tlili 5'); and Southern Tunisia ('Tozeur 1', 'Tozeur 4' and 'Harth Nafta').

The descriptors used in our study showed an important level of diversity in the local germplasm but were unable to discriminate between the germplasm according to geographic origin. Sorkheh et al. (2009), on the other hand, were able
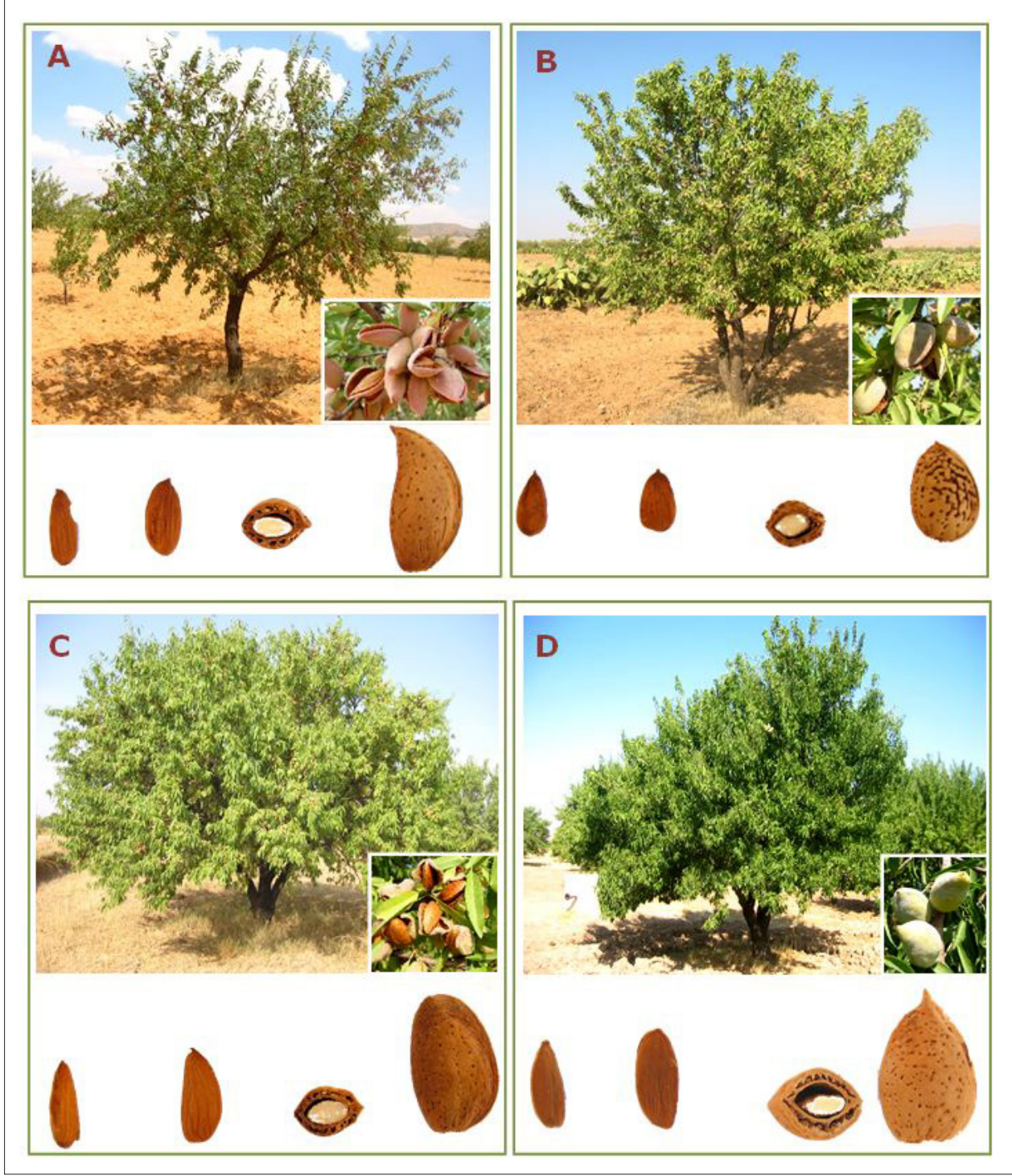

FIGURE 2. Details of growth habit, fruit and leaves of the local almond cultivars from Tunisia: 'Guernghzel C.H.' (A); 'Houcine B.N.' (B); 'Tlili 5' (C) and 'Bouchouka K.F.' (D). 
to use agronomic traits to associate the Iranian and non-Iranian genotypes according to their origin and genotypic relatedness. In recent works based on RAPD markers, cluster analysis clearly differentiated between the local Tunisian genotypes according to their origin (Gouta et al., 2008). A combination of molecular markers with morphological data would thus be a useful means to identify genetically distinct genotypes and the best choice for finding informative markers.

\section{Breeding prospects}

All genotypes presenting low rates of double kernels and aborted kernels can be preselected as parental for breeding programmes. The large variability observed in these traits is an indicator of a high level of genetic diversity among the almond genotypes studied. Several other authors have also observed a large diversity for these characteristics in almond but with different coefficient of variation levels, in other words, biometric kernel parameters like length, width and thickness showed the lowest coefficients, while double kernel and kernel yield showed the highest ones (De Giorgio et al., 2007; Fathi et al., 2008).

Although it is a negative trait, the self-incompatibility shown by all cultivars has the advantage of maintaining ge- netic variability within almond populations (Gradziel and Martínez-Gómez, 2013). In addition, early flowering is very common in Tunisia, and it seems that all farmers' early selections tend towards early blooming in order to cover this period of the year, when there is no other fruit, with fresh green almonds. This trait could be a problem in the case of late frost in spring (Dicenta et al., 1993). In addition, the nutritional status of the tree and low temperatures during flowering are both reasons for high double kernel rates (Egea and Burgos, 1995).

Shell softness and shelling percentage are two directly correlated parameters, and both are connected to important breeding issues. Hard shell genotypes are reported to be more resistant to insect and fungal infestation, while soft shell genotypes are highly susceptible to insect and fungal damage (Ledbetter and Shannard, 1992; Gradziel and Martínez-Gómez, 2002). The breeding strategy thus depends on the genotype used: in the case of soft shell genotypes, it is necessary to search for a source of insect and fungal resistance, whereas in the case of semi-hard shell genotypes, it is necessary to choose from the existing germplasm in order to preserve acceptable shelling rates.

The mentioned presence of double kernels is due to the fertilisation of the two ovules in the almond ovary. This is
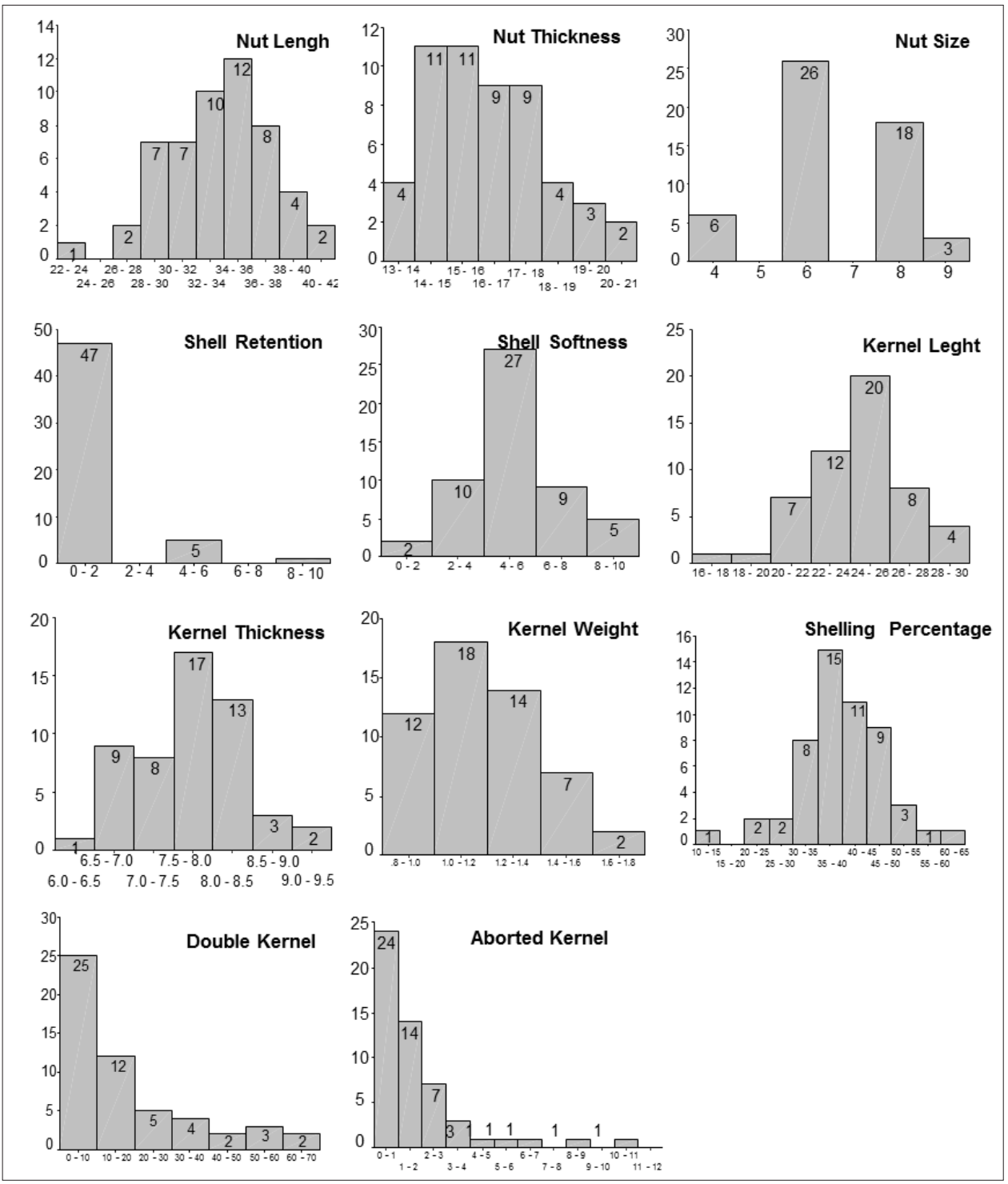

FIGURE 3. Distributions (number of genotypes) of kernel characteristics for the 53 almond genotypes assayed 

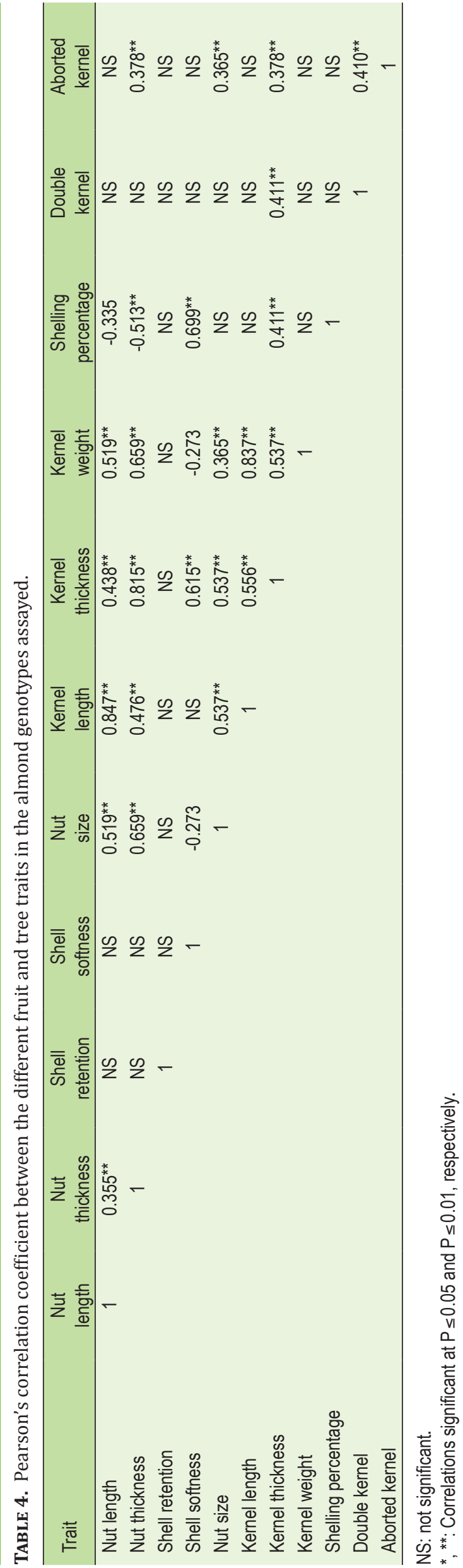

considered to be a negative trait, since it decreases fruit quality depending on the double kernel proportion (Kester et al., 1980). Nevertheless, the influence of the environment on the expression of this trait (especially low temperatures during the pre-blooming stage) has been well documented (Egea and Burgos, 1995; Artega and Socias I Company, 2001). The application of an equilibrated fertilizer program and the cultivation of these ecotypes in more clement zones may reduce this problem.

The kernel weight average (approximately $1 \mathrm{~g}$ ) observed in the Tunisian cultivars is common in many European and American cultivars, and such weight is a desired trait in breeding programmes (Gradziel and Kester, 1998). Some of the accessions in our study showed relatively high kernel weights, which resembled or even exceeded kernel weights of local and foreign commercial cultivars.

The extremely upright habit observed in our study can be used to meet less immediate breeding needs (Gradziel et al., 2002). In fact, extremely upright and upright genotypes are the main characteristics required for high and super high density systems, and the current tendency towards intensification in many species such as olive may affect almond in the near future, especially given that the first results have been so promising (Miarnau et al., 2013; Rius et al., 2013).

In agreement with these results, Egea et al. (2010) described the almond as one of the fruit tree species that best responds to reduced water in deficit irrigation programmes, maintaining its commercial value with a suitable kernel size. In addition, local Tunisian almond cultivars have proven to be more efficient than wild species, which show poorer agronomical behaviour (Gradziel et al., 2001; Sorkheh et al., 2007).

The small leaves observed (Figure 2) likely indicate adaptation to the xerophytic conditions (rainfall less than $150 \mathrm{~mm}$ per year). Similarly, Lansari et al. (1994) found that phenotypes collected from local almond populations in Morocco tended to have smaller leaves than introduced cultivars. This tendency was also observed in wild almond species in dry conditions in Iran (Sorkheh et al., 2009). Additionally, all genotypes studied are cultivated under rainfed conditions in areas with hot summers. The development of

TABLE 5. Principal component analysis in almond genotypes assayed. Eigenvectors and quantitative kernel traits percent of variation accounted by the first three PCs.

\begin{tabular}{lrrr}
\hline \multirow{2}{*}{ Variable } & \multicolumn{3}{c}{ Eigenvector } \\
\cline { 2 - 4 } & PC1 & PC2 & PC3 \\
\hline Nut length & 0.424 & 0.220 & -0.212 \\
Nut thickness & 0.410 & -0.152 & 0.286 \\
Nut size & 0.414 & 0.058 & 0.081 \\
Shell retention & -0.131 & 0.476 & 0.078 \\
Shell softness & 0.310 & -0.167 & 0.278 \\
Kernel length & 0.335 & 0.403 & -0.172 \\
Kernel thickness & 0.030 & -0.051 & 0.489 \\
Kernel weight & 0.249 & 0.466 & 0.166 \\
Shelling percentage & -0.330 & 0.356 & 0.223 \\
Double kernel & 0.060 & -0.453 & 0.399 \\
Aborted kernels & 0.243 & 0.008 & 0.139 \\
\hline Eigenvalues & 3.421 & 2.437 & 1.958 \\
Variance (\%) & 25 & 17 & 14 \\
Total variance (\%) & 42 & 56 & \\
\hline
\end{tabular}




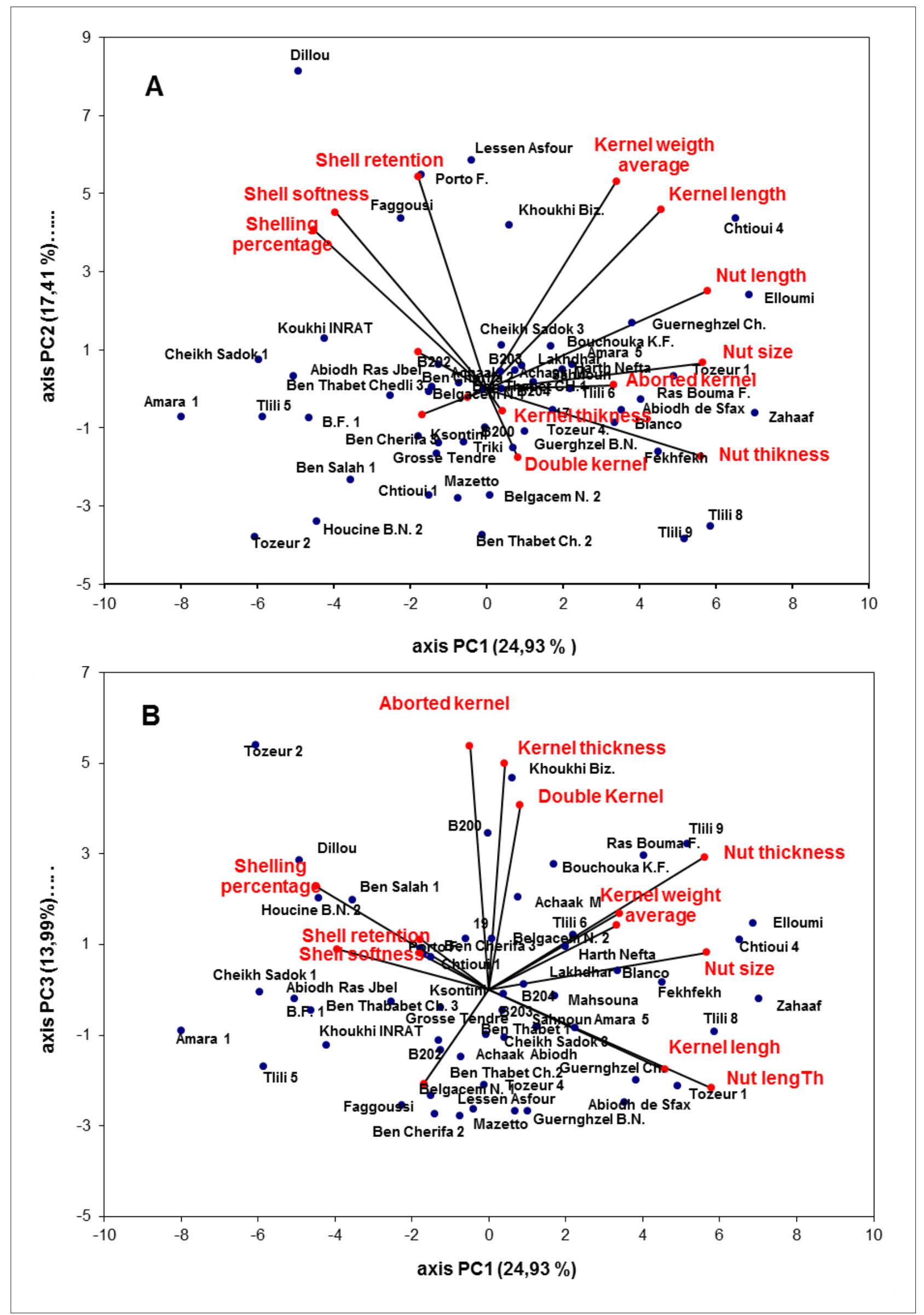

FIGURE 4. Segregation of the 53 almond genotypes according to kernel characteristics and their projections on the first and second factors of the component analysis (A) and on the first and third factors (B). 


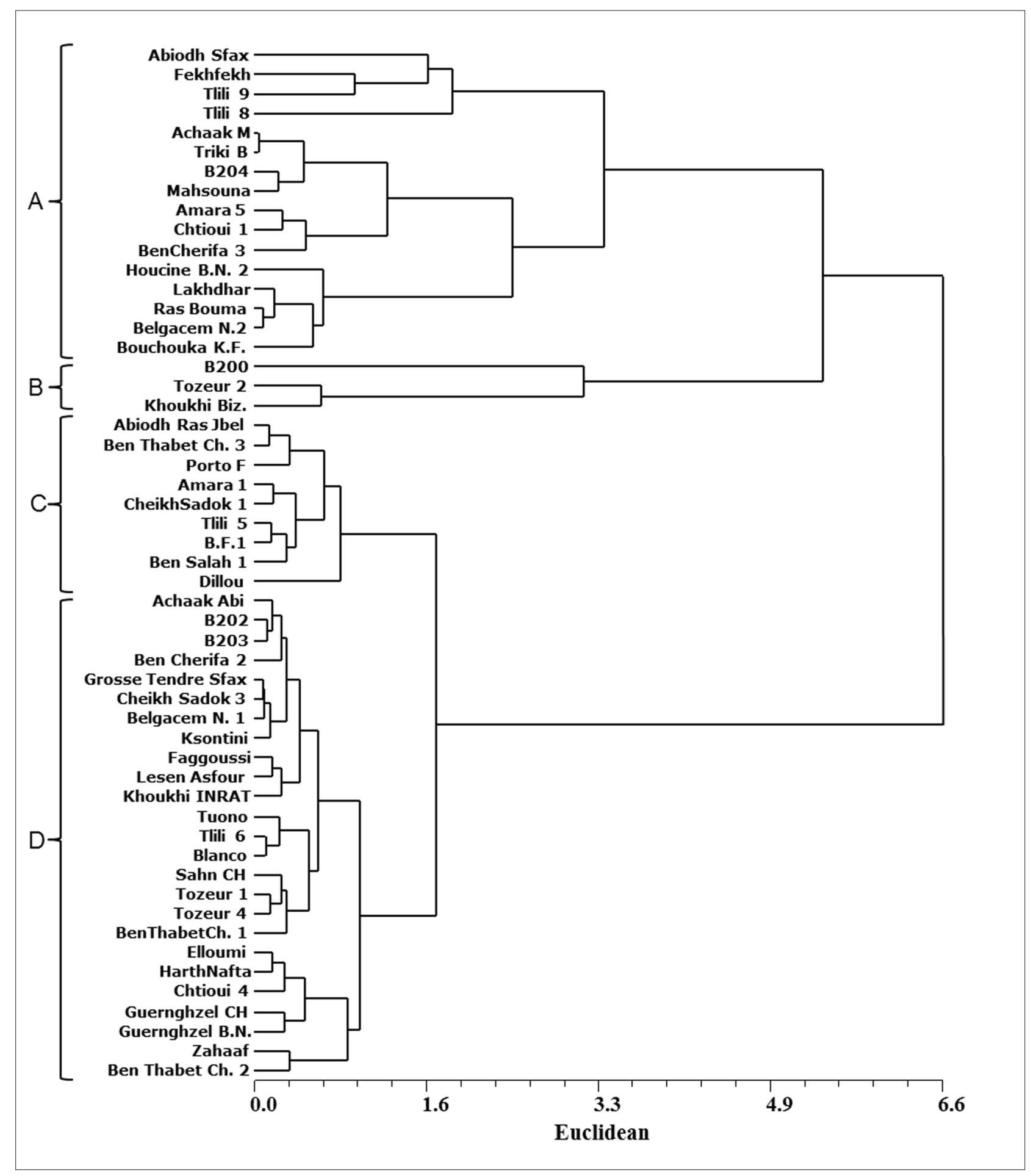

FIGURE 5. Dendrogram based on the Euclidean distance of morphological traits after standardisation of data for the 53 almond genotypes using NTSYS.

drought-resistant almond production systems using native Tunisian germplasm would therefore make more sustainable production possible, particularly in marginal areas with harsh climate conditions.

\section{Conclusions}

Results indicate that Tunisian almonds represent a rich source of new almond germplasm adapted to dry conditions, with rainfall around $150 \mathrm{~mm}$ per year. Furthermore, results also show the great pomological variation of local Tunisian almond cultivars and their breeding value for increasing national Tunisian almond production. In addition, the Tunisian almond germplasm studied is suitable for use in drought resistance breeding programmes, and it is also a potential source for selecting cultivars with a high shelling percentage, high kernel weight and low aborted kernel rates. The great diversity of growth habits is another trait of interest found in the local Tunisian cultivars. However, self-incompatibility, early flowering and the presence of double kernels are the most common obstacles to using 
this local germplasm in breeding programmes, although these undesirable traits could be eliminated in the selection process.

\section{Acknowledgments}

This research was supported by the Tunisian Ministry of Higher Education, Scientific Research and Technology and the European project 'Nut4Drought: Selection and characterization of drought resistant almond cultivars from the Mediterranean basin with high nutraceutical values'. The authors offer grateful thanks to Dr. Ziad Borji, Head of the Regional Centre for Agronomic Research in Sidi Bouzid.

\section{References}

Ak, B.E., Kuzdere, H., and Kaska, N. (2005). An investigation on phenological and pomological traits of some almond cultivars grown at Ceylanpinar State farm in Turkey. Options Méditerr. 63, 43-48.

Artega, N., and Socias i Company, R. (2001). Heritability of fruit and kernel traits in almond. Acta Hortic. 591, 269-274.

Badenes, M.L., Martínez-Calvo, J., and Lacer, G. (1998). Analysis of apricot germplasm from the European ecogeographical group. Euphytica 102, 93-99. https://doi.org/10.1023/A:1018332312570.

Chalak, L., Chehade, A., and Kadri, A. (2007). Morphological characterization of cultivated almonds in Lebanon. Fruits 62, 177186. https://doi.org/10.1051/fruits:2007013.

Čolić, S., Rakonjac, V., Zec, G., Nocolić, D., and Fotirić Aksić, M. (2012). Morphological and biochemical evaluation of selected almond [Prunus dulcis (Mill.) D.A. Webb] genotypes in northern Serbia. Turk. J. Agri. For. 36, 429-438.

De Giorgio, D., Leo, G., Zacheo, G., and Lamascese, N. (2007). Evaluation of 52 almond cultivars from the Apulia region in Southern Italy. J. Hortic. Sci. Biotechnol. 82, 541-546. https://doi.org/10.1080 /14620316.2007.11512271.

Dicenta, F., García, J.E., and Carbonell, E.A. (1993). Heritability of flowering, productivity and maturity in almond. J. Hortic. Sci. 68, 113-120. https://doi.org/10.1080/00221589.1993.11516334.

Egea, J., and Burgos, L. (1995). Double kernelled fruits in almond (Prunus dulcis Mill.) as related to pre-blossom temperature. Ann. Appl. Biol. 126, 163-168. https://doi.org/10.1111/j.1744-7348.1995. tb05012.x.

Egea, G., Nortes, P.A., González-Real, M.M., Baille, A., and Domingo, A. (2010). Agronomic response and water productivity of almond trees under contrasted deficit irrigation regimes. Agric. Water Manag. 97, 171-181. https://doi.org/10.1016/j.agwat.2009.09.006.

Fathi, A., Ghareyazi, B., Haghnazari, A., Ghaffari, M.R., Pirseyedi, S.M., Kadkhodaei, S., Naghavi, M.R., and Mardi, M. (2008). Assessment of the genetic diversity of almond (Prunus dulcis) using microsatellite markers and morphological traits. Iran J. Biotechnol. 6, 98-106.

García, M.C., González-García, E., Vásquez-Villanueva, R., and Marina, M.L. (2016). Apricot and other seeds stones: amygnalin content and the potential to obtain antioxidant, angiotensin I converting enzyme inhibitor and hypocholesterolemic peptides. Food Funct. 7, 4693. https://doi.org/10.1039/C6F001132B.

Gouta, H., Ksia, E., Zoghlami, N., Zarrouk, M., and Mliki, A. (2008). Genetic diversity and phylogenetic relationships among Tunisian almond cultivars revealed by RAPD markers. J. Hort. Sci. Biotechnol. 83, 707-712. https://doi.org/10.1080/14620316.2008.11512448.

Gouta, H., Guenichi, H., Rezgui, R., Mars, M., Zarrouk, M., and Mliki, A. (2010). Systèmes de production et ressources génétique de l'amandier (Prunus dulcis L.) dans le Centre-West Tunisien. Revue des Régions Arides 24, 106-111.
Gouta, H., Mares, M., Gouiaa, M., Ghrab, M., Zarrouk, M., and Mliki, A. (2011). Genetic diversity of almond (Prunus amygdalus Batsch.) in Tunisia: A morphological traits analysis. Acta Hortic. 912, 351-358. https://doi.org/10.17660/ActaHortic.2011.912.51.

Gouta, H., Ksia, E., Buhner-Zaharieva, T., Mliki, A., and Gogorcena, Y. (2012). Development of an SSR-based identification key for Tunisian local almonds. Sci. Agric. 69, 108-113. https://doi.org/10.1590/ S0103-90162012000200004.

Gradziel, T.M., and Kester, D.E. (1998). Breeding for self-fertility in California almond cultivars. Acta Hortic. 470, 109-117. https://doi. org/10.17660/ActaHortic.1998.470.15

Gradziel, T.M., and Martínez-Gómez, P. (2002). Shell seal breakdown in almond is associated with the site of secondary ovule abortion J. Am. Soc. Hortic. Sci. 127, 69-74. https://doi.org/10.21273/ JASHS.127.1.69.

Gradziel, T.M., and Martínez-Gómez, P. (2013). Almond breeding. Plant Breed. Rev. 37, 207-259. https://doi.org/10.1002/9781118497869.ch4.

Gradziel, T.M., Martínez-Gómez, P., Dicenta, F., and Kester, D.E. (2001). The utilization of Prunus species for almond variety improvement. J. Am. Pomol. Soc. 55, 100-108.

Gradziel, T.M., Kester, D.E., and Martínez-Gómez, P. (2002). A development based classification for branch architecture in almond. J. Am. Pomol. Soc. 56, 106-112.

Grasselly, Ch., and Crossa-Raynaud, P. (1980). L'amandier (Paris, France: Eds. Maisonneuve et Larose).

Hjalmarsson, I., and Ortiz, R. (2000). In situ and ex situ assessment of morphological and fruit variation in Scandinavian sweet cherry. Sci. Hortic. 85, 37-49. https://doi.org/10.1016/S0304-4238(99)00123-

Kester, D.E., Micke, W.C., Rough, D., Morrison, D., and Curtis, R. (1980). Almond variety evaluation. California Agric. 34, 4-7.

Krahl, K.H., Lansari, A., and Iezzoni, A.F. (1991). Morphological variation within a sour cherry collection. Euphytica 52, 47-55.

Lansari, A., Iezzoni, A.F., and Kester, D.E. (1994). Morphological variations within collections of Moroccan almond clones and Mediterranean and North American cultivars. Euphytica 78, 27-41.

Ledbetter, C.A., and Shannard, C.B. (1992). Evaluation of selected almond (Prunus dulcis (Miller) D.A. Webb) germplasm for several shell and kernel characteristics. Fruit Var. J. 46, 79-82.

Miarnau, X., Montserrat, R., Battle, I., and Vargas, F.J. (2013). High density planting in almond orchards. VI Int. Symp. on Almonds and Pistachios, Murcia (Spain), May 2013.

Musa-Velasco, K., Paulionis, L., Poon, T., and Lee, H.Y. (2016). The effect of almond consumption on fasting blood lipid levels: a systematic review and meta-analysis of randomised controlled trials. J. Nutr. Sci. 5, e34. https://doi.org/10.1017/jns.2016.19.

Nikolić, D., Rakonjac, V., Milatović, D., and Fotirić, M. (2010). Multivariate analysis of vineyard peach [Prunus persica (L.) Batsch.] germplasm collection. Euphytica 171, 227-234. https://doi. org/10.1007/s10681-009-0032-3.

Poonam, V., Raunak, G., Kumar, C.S., Reddy, L., Jain, R., Sharma, S.K., Prasad, A.K., and Parmar, V.S. (2011). Chemical constituents of the genus Prunus and their medical properties. Curr. Med. Chem. 18, 3758-3824. https://doi.org/10.2174/092986711803414386.

Rius, X., Bordas, M., and Torrents, J. (2013). Super high density almond orchards. VI Int. Symp. on Almonds and Pistachios, Murcia (Spain), 27-31 May.

Rohlf, J.F. (2004). NTSYS-pc: 2.11 Numerical Taxonomy and Multivariate Analysis System (New York, USA: Exeter Software) 
Sánchez Pérez, R., Ortega, E., Dual, H., Martínez-Gómez, P., and Dicenta, F. (2007). Inheritance and relationships of important agronomic traits in almond. Euphytica 155, 381-391. https://doi. org/10.1007/s10681-006-9339-5.

Sorkheh, K., Shiran, B., Gradziel, T.M., Epperson, B.K., Martínez-Gómez, P., and Asadi, E. (2007). Amplified fragment length polymorphism as a tool for molecular characterization of almond germplasm: genetic diversity among cultivated genotypes and related wild species of almond, and its relationships with agronomic traits. Euphytica 156, 327-344. https://doi.org/10.1007/s10681-007-9382-x.

Sorkheh, K., Shiran, B., Rouhi, V., Asadi, E., Jahanbazi, H., Moradi, H., Gradziel, T.M., and Martínez-Gómez, P. (2009). Phenotypic diversity within native Iranian almond (Prunus spp.) species and their breeding potential. Genet. Res. Crop Evol. 56, 947-961. https://doi. org/10.1007/s10722-009-9413-7.

Sorkheh, K., Shiran, B., Khodambashi, M., Moradi, H., Gradziel, T.M., and Martínez-Gómez, P. (2010). Correlations between quantitative tree and fruit almond traits and their implications for breeding. Sci. Hortic. 125, 323-331. https://doi.org/10.1016/j. scienta.2010.04.014.

Talhouk, S.N., Lubani, R.T., Baalbaki, R., Zurayk, R., Al-Khatib, A., and Parmaksizian, L. (2000). Phenotypic diversity and morphological characterization of Amygdalus L. species in almond. Genet. Res. Crop Evol. 47, 93-104. https://doi.org/10.1023/A:1008763021129.

Received: Mar. 28, 2017

Accepted: May 30, 2017

Addresses of authors:

H. Gouta ${ }^{1}$, E. Ksia ${ }^{2}$, M.M. Ayachi ${ }^{1}$ and P. Martínez-Gómez ${ }^{3, *}$

${ }^{1}$ Olive Tree Institute, P.O. Box 1084, 3000 Sfax, Tunisia

${ }^{2}$ Laboratoire de Biologie des Plantes et Biotechnologies, Faculté des Sciences, Campus Universitaire, El Manar, 1060 Tunis, Tunisia

${ }^{3}$ Department of Plant Breeding, CEBAS-CSIC, P.O. Box 164, 30080 Espinardo, Murcia, Spain

* Corresponding author; E-mail: pmartinez@cebas.csic.es 